\title{
THE ACCOUNTING AND FISCAL APPROACH OF MICRO-UNITS AS AN INFORMALITY RATE AND REDUCTION TOOL
}

\author{
Ilda Kadrimi (Blaceri) $)^{399}$
}

https://doi.org/10.31410/itema.2018.1155

\begin{abstract}
Micro-units are one of the main forms of business organization in the world and in Albania. Undertaking policies to reduce informality and tax evasion is a direct benefit to the Albanian economy in the context of the importance and contribution that these entities bring to the state budget. Micro-units currently have a simplified reporting framework under SKK 15 and are implemented in the framework of the approximation of Albanian legislation with that of the European Union. The accounting reporting of these units is not seen as a driving force for informality or fiscal evasion. On the other hand, in terms of fiscal reporting and existing fiscal laws, there is an opportunity to improve them as a way to reduce fiscal evasion and informality of micro-units. This conclusion comes in the context of the case study which deals with the legal vacuum in the law of VAT that brings inequality against taxpayers. Its elimination is argued by undertaking the policy of removing the exclusion threshold for annual turnover in the trade sector, as the questionnaire also finds the biggest problems in the sector. The key recommendations are needed to be directly implemented in the law on VAT and at the same time to adopt an action strategy to eliminate the negative effects that bring the main factor in promoting fiscal informality and evasion, which is the tendency for non-disclosure of the real financial situation as a way to pay less taxes. Taking these two recommendations would also have an indirect effect on reducing national informality and tax evasion.
\end{abstract}

Keywords: Business, accounting reporting, fiscal reporting, informality, tax evasion

\section{INTRODUCTION}

$\mathrm{M}$

icro-units have a very crucial role in the economic growth and stable development of a country (Moore, 2008). Having such an indicative influence, the focus toward this category should be maximal in government policies which improve the business climate for these units and special attention should be paid to problems that this section faces every day. Meanwhile, tax evasion is the process of giving fake tax declarations. For the first time, about tax evasion is written in 1968, by the remarkable economist Gary Becker, in the "Crime Economy" edition on the basis of which authors MG. Allingham and A.Sandmo built, in 1972, the economic model of tax evasion. This model deals with tax evasion over income. Because of tax evasion, taxpayers deliberately distort their real amounts on their accounts in tax organs to diminish their tax obligation and they're included in the dishonest taxes reporting, such as declaring less income; profits or lower profits than actual gained amounts, etc. Tax evasions are a juristic reorganization of a business so that this business might minimize as much as possible its tax obligation to the limit that the law permits, whereas tax evasion can be seen as a whole reorganization for the business, for the same purpose, but that surpasses even legal limits.

\footnotetext{
${ }^{399}$ Lecturer, Albanian University, Albania
} 
The identified percentage of tax evasion is much lower compared to the total size of tax evasion, including informal economy tax evasion, which is totally unidentified. Tax evasion is present in the formal economy as well as in the informal one, but it is more present in the informal economy. Meanwhile, the opposite cannot happen. Based on the above conclusion, a unit that can commit tax evasion may be formal or not.

Informality has been in the center of the fields with interest for many different scientific researchers and it has appeared in different forms during different time periods. Its identification and reduction is very important for the economic and social development of a country and for the government policies effectivity, but its evaluation and elimination is very difficult to achieve. For this reason, informality and the whole informal economy has become an important case in national and international levels especially in view of the European integration.

In the action taken for the informality in Albania, during the end of 2015, a very high number of informal businesses were identified, and they were registered as regular taxpayers. From data published in official statistics it is estimated that the number of people registered as a consequence of this action is increased by $40 \%$. The action was focused mainly in micro-units which were identified as a category with high informality rate and the achieved results prove such a fact. On the other hand, there were some attempts to fight tax evasion in registered units mainly confirmed through the change of tax responsibilities for a taxpayers' category, and on the other side of employees increase in micro-units' payrolls. With all the encouraging results of the action, we reach a conclusion that shows that informality and evasion are in high levels for these categories. Besides the results and statistics, it's important to have a proper strategy to fight these disturbing phenomena for a very important category of Albanian enterprises. In terms of such indicators the natural question rises on which are the main fiscal and reporting problems for these micro-units in Albania today. Also, the purpose for the undertaking of this study is to offer some tools for the resolution of reporting and fiscal issues and for micro-units as condition for mutual profit of the state and these economic units. Thus, the purposes of this paper are:

- To show the existence of issues in the legal and fiscal framework of the activity exercise of micro-units.

- To enable the finding of solutions for the formalization and avoidance of tax evasion in micro-units, based on the main causes that stimulate such a thing in the own perception of entrepreneurs.

The main researching question of the study has to do with the accounting and tax regulating framework as a stimulant of informality and tax evasion in Albanian micro-units. So, in other words, does the accounting regulation or the existing tax framework affect as a stimulant of informality and tax evasion in the micro-units' category? To make every case simpler and more precise, other research sub questions are formulated. To these sub questions, according the appropriate treatment, is given an answer through studying of the literature, a study case and the testing of an organized questionnaire relating the perception of entrepreneurs of this category.

\section{ACCOUNTING AND FISCAL REPORT OF MICRO-UNITS - REVIEW OF THE LITERATURE}

Micro-units are usually family businesses or self-employed people who exercise their activity in partially formalized or not formalized sections of the economy. Some of them have less chances to convert to big firms mainly as a consequence of low crediting opportunities from 
the banks and for international expansion. The legal and accounting regulation of these units often requires particular institutions and specific instruments. An example of this differentiated approach is the loan oriented in methods based on applied groups from some micro-financial crediting institutions (Hallberg, Vol. 63).

The micro-units, in the definition provided by different authors, have a separate designation regarding the criteria that are used for the evaluation of this form. Until 2000s, such a category was not clearly identified even from fiscal standards or laws in different countries of the world or even from different researchers of the field. The few researches in this field started to be conducted in the groups of small and medium sized enterprises and often including the group of these units too in this large group without identifying the need for simplified procedures of reporting that this category has. According BSNK, small and medium sized units can be divided into three categories, micro, small and medium sized. The main requests for small and medium sized economic units are:

- These economic units don't have a public responsibility.

- They prepare financial statements for generic purposes (BSNK, 2010)

Meanwhile in the quantitative criteria, variables like the employees' number, annual realized circulation and/or the size of the financial position statement are taken into consideration. The recommendations for the proper and estimate definition of this category is for a combination of these two criteria to be used so that standards and policies might be drafted in their direct profit. This is because studies show that there's a difference between micro-units according different countries, sections they operate, the economic development rate, etc. Even inside a specific country, micro-units are not a homogenous structure because even the criteria for their identification are a combination of quantitative and qualitative variables in the same time.

Another logical division might also be the classification in micro-units with the possibility for growth and in micro-units which are limited to growth. Such an argument is supported by the fact that many big global firms enlisted in international grants have begun as this organization form; just to mention examples like McDonald's. So, every categorization and direct definition for micro-units that make their classification for the separation from the group of small and medium sized enterprises, might be arbitrary, taking into consideration the problems or limitations that such consideration hold on the basis of quantitative or qualitative criteria set by organisms to adapt to. (Demartini 2005)

\section{II.1. Accounting report of micro-units in Albania.}

In Albania too, micro-units have a clearly defined treatment referring to the National Accountability Standard 15 in which directives from the European Council are implemented for a simplified reporting of these economic units. The standard for these units makes a division according the reporting requests by designating as evaluation criteria the legal form of the economic unit, the annual circulation rate, the employees' number, and the value of the asset of the financial performance declaration. According the designation of the standard, two conditions must be met from the three criteria that are designated for the two last years of exercising economic activity by the economic unit. From these criteria, we mention the employee' number that shouldn't be higher than 10 people and also the figure of the business and/or the total of the asset to 10 million Lek. It is enough for one of the two criteria about the size of the annual balance or circulation to be accomplished together with the criteria of 
employee's number for the last two years and the units are subjects of this standard's implementation.

In the $5^{\text {th }}$ paragraph of the standard implementation field is defined the simplified accountability with a one-fold monetary base as a basis for the registration of transactions that are made by individuals with an annual income up to 2 million. All other micro-units, regardless of the legal form, keep their records according the increasing accountability. This is a division that's been applied in the case of Albania to offer a simplification in reporting also based in the cost-profit criteria of the information produced by units with an annual circulation under 2 million.

Referring to the European Council's directive over the simplified reporting of micro-units, this is an opportunity where it's given independence of choice to the states regarding the choice of the accountability application on a one-fold monetary base or the application of the double registering method for all the micro-units group. A differentiated accounting approach, according SKK 15, offers the basic argument regarding the answer to the second research question regarding the simplified reporting of micro-units also implemented in Albania on the basis of preliminary criteria that bring the existence of this business organization form.

\section{II.2. Fiscal reporting and contribution in the national income by micro-units in Albania.}

Also, in the Albanian economy, micro-units play a big role in the economic development, taking into consideration their existence and their state of economic development. In the first part of the paper we identified the accountability approach that this category of entrepreneurship has in the world and in Albania. Following this is identified the fiscal approach in which microunits are part as a way to show the contribution they bring to the national economy and on the other hand to create a fairer picture regarding problems of their fiscal reporting through problems that appeared in the past and from the direct reasoning.

An entity that's specified as a micro-unit according the national accountability standard 15, will be specified for the purpose of income taxes as a small business if it achieves an annual circulation under 8 million all during a calendar year. Being a subject of such a definition, this business category offers a differentiated approach compared to subjects with a greater circulation than this rate. This is because the small business is a subject of the simplified profit tax which has lower rate than the income tax that's achieved by the business. For the year 2015, the tax for unit subjects of the simplified tax for the little business was:

Table 1 Chart for the simplified tax over the small business before the change

\begin{tabular}{|l|l|}
\hline Annual Circulation & Profit tax of the small business \\
\hline $0-2000000$ ALL & 25000 ALL \\
\hline $2000000-8000000$ ALL & $7.5 \%$ of the profit but not less than 25000 ALL \\
\hline \multicolumn{2}{|c|}{ Source: The law on the simplified tax of the small business } \\
\hline
\end{tabular}

With a decision made in the end of 2016, further facilitations are proposed for this category by rebuilding the chart as following:

Table 2. Chart for the simplified tax over the small business after the legal change

\begin{tabular}{|l|l|}
\hline Annual Circulation & Profit tax of the small business \\
\hline $0-5000000$ ALL & 0 \\
\hline $5000000-8000000$ ALL & $5 \%$ of the profit \\
\hline \multicolumn{2}{|c|}{ Source: General Directorate of Taxation }
\end{tabular}


Contributions for social and health care. Mainly, for the categories taken in the study are the levels of the applied rates for the self-employed individuals according the designation of the law for contributions.

Regarding the micro-units' informality or their tax evasion, there's a perception regarding the low importance they have in the macroeconomic contribution for the state's budget from the field's scholars. Mainly, this conclusion is reasoned upon the contribution that these units bring in the Albanian state's budget regarding the simplified tax over the small business. However, such an argument would be premature taking into consideration the entirety of the taxes mentioned above that these units pay for. Moreover, another argument that strengthens this conviction is also the effect that the evasion formalization or reduction for these units has in the other links of the biggest enterprises that enter the transactions with these units. Specifically talking, for each of the above-mentioned taxes is given the adapt argument and the effect that different taxing policies have over these units and in total in the national economy.

\section{ISSUES OF THE FISCAL APPROACH OF MICRO-UNITS}

The change of the tax's responsibility is a debatable case also referring to the designation in the changed law for the VAT since there's no clear designation regarding the criteria of the obligatory passing as a subject of this law. This legal vacuum is also strengthened from the fact that our tax system is built on the principle of self-declaration and on the other hand there's a high evasion rate in this field regarding the non-declaration of the real annual circulation. This creates a redundancy of the businesses that are hiding in this category and abuse with the profits of being under the excluding threshold for the VAT.

These changes are a main object of this paper and they'll be dealt with in the following sections. It's exactly the perception of the entrepreneurs of this changed category that will be studied and put in a parallel with other factors that will be identified in the following sections. The approach chosen to use for this concept in the paper has to do with the level of the threshold for registration in the requirement of the law of the Value Added Tax of the Republic of Albania. According the definitions made in the law, we identify that the obligation to register for this tax it's on the following subjects:

- Free professions (advocate, accountant, lawyer, immovable property registrant, chemist), regardless of the annual circulation rate.

- Subjects that realize activities in the area of hotels regardless of the annual circulation rate

- All the subjects who carry out imports in the Republic of Albania and are registered as resident taxpayers, as businesses regardless of the annual circulation they have realized.

- All the subjects who surpass the threshold of the registration in the Republic of Albania that is appointed with the decision of the Minister of Finance and is published in the website of the Ministry of Finance. Currently, this threshold of the procreation of the obligation for registration in the Value Added Tax is appointed in the level of $20 \%$ and for all of those businesses that carry out a circulation over 5 million Lek during the calendar year.

The point that is focused on in this work and that it's more valuable regarding the purpose of the paper's realization, has to do with the last point in which the appointed threshold is given for registration in the VAT. The focus group, just as it was identified above, are mainly microunits which will be tested and conclusions made from the study of the literature. 
As it was mentioned before, one of the biggest current issues is informality and tax evasion in Albania that appears in the forms of:

- Non-declaration of employees,

- Non-registration of the activity,

- Non-declaration of the actual turnover in Albania, mainly by micro-units.

In these conditions when the declared turnover is not real, then we're dealing with abuses in this category and with profits off the subjects that are not legal for these benefits. The concealment in this category is the main tool of evasion from the micro-units. But which is the way to fight such a phenomenon? Generally speaking, micro-units are represented by retail units, service units, handicraftsmen, the self-employed in different professions, restaurants, bars, etc. Our law for the VAT has clearly defined the involvement as a subject of the law of profession categories or economic units that exercise their economic activity in the area of hotels. Under these conditions why not making such a definition also for retail units and service units and have specific categories of professions that in fact don't pass the threshold? In the foundation of the legal change proposed, let criteria such as these remain: the object of the exercised activity is more in the orientation of the offering of the service offering or trading of the products? The exclusions to exist with thresholds but only for those units whose activity is mainly based in works such as production factors, and with national importance such as the handicraftsman section. However, besides the benefits, such a legal change would also have some opposite arguments which are referred to the possible solution as a counterargument to prove the surpassing of profits from the costs. Second, besides the costs, such a change will bring even more additional procedures relating the fiscal report. And last, all the statements process, that of the supervision, will also engage more funds and resources on the tax administration side. In view of these changes, the purposes of undertaking such a proposal must remain. Such an initiative, that's been previously argued about, will directly contribute in the reduction of tax evasion on the basis of previously made definitions, one of the main issues of enterprises in the current conditions of Albania.

On the other hand, through this study case, the negative effect was proved, that the excluding threshold has in the equality between taxpayers. In the conditions when a taxpaying group has homogenous attributes regarding the kind of activity and likeliness or the sameness of products that are traded, such a legal regulation will provide the adherence of one of the foundational principles over which our taxing system is built, which is the equality between taxpayers, according the regulations in the law for tax procedures in the Republic of Albania. Also, a proposal for taking under control of the reporting costs from the taxpayers and in the same time the tax administration, would be that the reporting system doesn't need intervention since the data transmission is actually accomplished through the equipment with fiscal cash register. Since the taxpayers are equipped with these tools and on the other hand they make daily reports of sales, then there's no need for an addition cost in the sales process.

As for the purchases report, a solution might be their reporting on a 3-months basis to not cause high added cost, or offering of the assistance through guidelines from the tax administration regarding this process for the entrepreneurs in micro-units. While the taxing management can be done with reduced costs by making a good use of the current informatics system of reporting sine it enables such a thing on a wide base of users. Promising results can also come from the permanent staffs' engagement specifically for this category in the tax directories' structure. The costs that will come as a result of the taxing management, because of above-mentioned arguments, will be covered from additional income in all kinds of previously treated taxes. 
In conclusion of this case, legal vacuums are identified that are used as an argument relating the research question for fiscal issues of micro-units' reporting. The case study also brought a fact in the way the law itself creates premises for tax evasion in the approach it offers to taxpayers in sections with competition and with prices that are somewhat fixed. The given recommendations in this chapter and the logic flows from the interpretation of the findings, are an invaluable strategy regarding the reduction of these undesired effects, also taking into consideration the cost-profit ratio from such initiatives.

\section{CONCLUSIONS AND RECOMMENDATIONS}

The category of micro-units plays a great role in the economic development of countries and the support for them with favoring policies is a direct benefit in the tax income for countries' budgets, increase of employment, democratization of countries, the fairest distribution of income, etc. Since issues like tax evasion and informality for these units exist, the undertaking of initiatives to eliminate them would be a very great help for this category.

Micro-units have a well-defined accounting regulation through the European Union's directive for this category. Even in Albania we have adapted the legislation for the accounting report of these units like in the EU through SKK 15. Their reporting in this framework is simplified as a consequence and as a need for less information for users.

In Albania, there's a differentiated approach also from the fiscal party for this business category. The contribution that these units bring in the state's budget is through taxes, fees and contributions that are evaluated in high levels. The informality of this section was higher before September 2015 that was proved with new registrations through the addition with $40 \%$ of the micro-unit taxpayers.

The actual fiscal framework offers conditions for the stimulation of tax evasion and informality in micro-units, and this is proved through the case study regarding the registration threshold for the VAT, that brings a differentiating treatment of taxpayers in the same conditions. This is the case of Albania, where also the rate of income concealment is in a high level and many businesses hide under the excluded category as a subject of this law, bearing privileges in reporting and from the monthly non-declaration of sales and purchases booklets. In the same line is also evaluated the latest legal initiative that zeroes the profit tax of the small business, argued as a way of the addition of abuse from micro-units through the fragmentation of the activity.

Most of the entrepreneurs don't know the difference between the concepts of informality and tax evasion. Asked regarding the form of informality display, these entrepreneurs responded for the concealment of the sales and the differentiated treatment that the law of the VAT offers. With the undertaking of the anti-informality action, almost half of the micro-units haven't been affected. Meanwhile, the others have registered the informal business they owned before the action, and a part of them have changed their tax responsibility. Most of the interviewed, previously informal, are in the circulation rate under 2 million Lek and they belong to the trading section. Whereas, the tax responsibility is changed in most of them, not with the taxpayers' request themselves, but with subjectivity in the interpretation of the law from the tax administration representatives. This also testifies the necessity of the incorporation of trading subjects in the VAT scheme, regardless their realized circulation.

The most important factor that stimulates evasion, according the perception of entrepreneurs, is evaluated to be the desire and will to not expose the real financial condition so that less taxes 
and fees might be paid. Meanwhile, two other important factors that are evaluated in the perception of the entrepreneurs are the intensity of the laws change and fiscal regulations, and the existing fiscal framework.

\section{REFERENCES}

1. Allingham, M. G. and A. Sandmo (1972). - 'Income Tax evasion: A Theoretical Analysis', Journal of Public Economics, Vol.1, p.323-38,

2. Collis, J. and R. Jarvis (2000). How owner-managers use accounts, Centre for Business Performance, ICAEW. London: IFRS Foundation Publications Department.

3. Creswell, J. W. (2008) Educational research: Planning, conductingand evaluatin qualitative and quantitative research ( $3^{\text {rd }}$ edition)

4. Dhamo. S (2014)Kontabiliteti financiar

5. Demartini, P. (2005). Accounting harmonization for European small businesses. Quaderni di Economia Aziendale (Working Papers), Urbino University, Italy.

6. European Parliament \& Council of the European Union. (2012). Directive 2012/6/EU of the European parliament

7. European Parliament \& Council of the European Union. (2013). Directive 2013/34/EU of the European parliament

8. Eurofast (2015), Croatia tax card, Serbia tax card, Montenegro tax card, Romania tax card, Macedonia tax card retrieved from www.eurofast.eu

9 .Gary Becker (1968). "Crime and Punishment: An Economic Approach" - The Journal of Political Economy76: p. 169-217

10. Hoxha. E, (2014), Raportimi financiar i njësive të vogla dhe te mesme, P.16

11. Ivana Mamić Sačer, Nikolina Dečman \& Ivana Sever (2015) The influence of accounting regulation simplification on the financial reporting of micro entities - the case of Croatia 12. IFAC (2007), Micro-entities financial reporting, Perspectives of prepares and users 